\title{
USING STATIC POLYNOMIAL LOAD MODELS IN "RASTRWIN" SOFTWARE PACKAGE FOR POWER SYSTEM STUDIES
}

\author{
Aleksey Pankratov ${ }^{1}$, Mikhail Kondrashov ${ }^{1 \mathrm{a}}$, Svetlana Paul ${ }^{2}$ \\ ${ }^{1}$ National Research Tomsk Polytechnic University, 634050 Tomsk, Russia \\ ${ }^{2}$ National Research Tomsk State University, 634050 Tomsk, Russia
}

\begin{abstract}
Polynomial load model practical application has some specificity. Per unit static load model dependence on node rated voltage value is demonstrated in this paper. The assigned rated voltage values of load nodes with polynomial characteristics are to be invariant to avoid calculation complementary error appearance. If rated voltage correction is necessary condition, for example to obtain calculation convergence, the active and reactive power drawn under rated voltage and polynomial coefficients must be corrected too. Correcting calculation expressions are presented in the paper.
\end{abstract}

\section{Introduction}

Load modeling is necessary for power system management. Different load model modifications are established [1-3], but problems of its practical application are described not so particularly.

The basic simulation tool, using by the System Operator of the Russian United Power System, is "RastrWin" software package [4]. Electric loads are presented by per unit polynomial static load models in this package. Base voltage, active and reactive power are used to convert values to per unit system.

Practical calculations of power system mode parameters often demand nodes base voltage changing. In result static load models have difference from original characteristics, and calculation complementary error appears. There is no description of this problem and its solution in literature.

\section{Experimental setup and study technique}

Simple radial network, supplying cable factory "Sibkabel" of Tomsk city, was modeled in the "RastrWin" software package. Static load models in "RastrWin" are described by expressions

a Corresponding author: mihail-arhange10@mail.ru 


$$
\begin{aligned}
& P(U)=P_{B A S} \cdot\left(a_{0}+a_{1} \cdot \frac{U}{U_{B A S}}+a_{2} \cdot\left(\frac{U}{U_{B A S}}\right)^{2}\right), \\
& Q(U)=Q_{B A S} \cdot\left(b_{0}+b_{1} \cdot \frac{U}{U_{B A S}}+b_{2} \cdot\left(\frac{U}{U_{B A S}}\right)^{2}\right),
\end{aligned}
$$

where $P_{B A S}, Q_{B A S}, U_{B A S}$ - base active and reactive power and base voltage; $a_{0}, a_{1}, a_{2}, b_{0}, b_{1}, b_{2}-$ per unit polynomial coefficients. Load node rated voltage is used as base voltage. But rated voltage term differs from classical interpretation in "RastrWin" software package. Thus using node rated voltage values can vary from the standardized quantities.

Original static load model parameters were obtained in active experiment with base voltage $U_{B A S 1}=6.2 \mathrm{kV}$ and are presented in Table 1 .

Table 1. Polynomial load model coefficients, base active and reactive power with $U_{B A S 1}=6.2 \mathrm{kV}$

\begin{tabular}{|c|c|c|c|c|c|c|c|}
\hline \multicolumn{3}{|c|}{ Active power } & \multicolumn{4}{c|}{ Reactive power } \\
\hline$a_{0(1)}$ & $a_{1(1)}$ & $a_{2(1)}$ & $P_{\mathrm{BAS}(1)}, \mathrm{MW}$ & $b_{0(1)}$ & $b_{1(1)}$ & $b_{2(1)}$ & $Q_{\mathrm{BAS}(1)}, \mathrm{Mvar}$ \\
\hline 1.481 & -2.277 & 1.796 & 1.4 & 52.048 & -108.651 & 57.599 & 0.7 \\
\hline
\end{tabular}

Other "Sibkabel" load node rated voltage value $U_{B A S 2}=6.0 \mathrm{kV}$ was set in "RastrWin" software package to demonstrate base voltage influence on static load model.

\section{Experimental results}

Series of steady state mode calculation were made with different load node voltage values, and active and reactive power values were noted. Obtained results and original polynomial load models are shown in Fig. 1. Load models difference is explained by using different base voltage values: $U_{B A S 1}=6.2 \mathrm{kV}$ for original characteristics and $U_{B A S 2}=6.0 \mathrm{kV}$ for "RastrWin" software package.

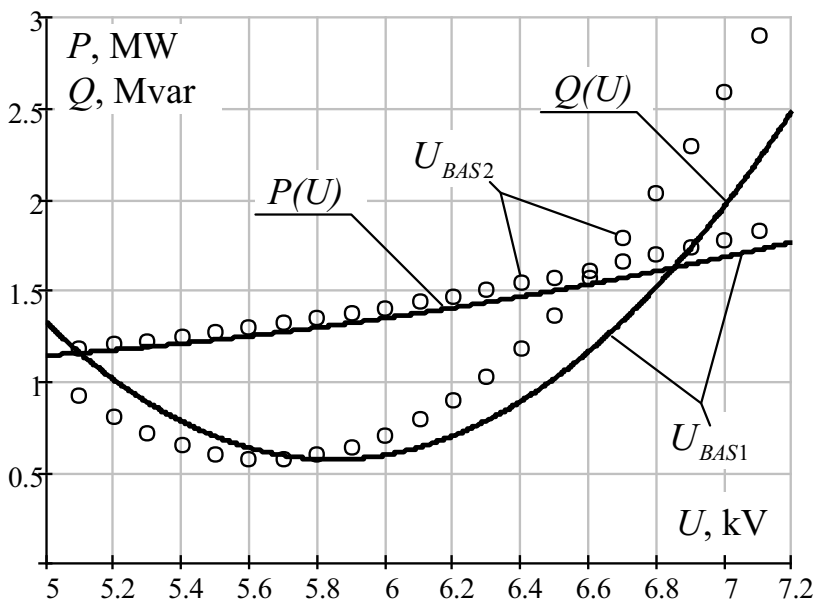

Figure 1. Original static load models with $U_{B A S 1}=6.2 \mathrm{kV}$ and "RastrWin" series of steady state mode calculation results with $U_{B A S 2}=6.0 \mathrm{kV}$ 
Fig. 1 demonstrates impropriety of load node base voltage $U_{B A S}$ changing without base active $P_{B A S}$ and reactive $Q_{B A S}$ power and per unit polynomial coefficients $a_{0}, a_{1}, a_{2}, b_{0}, b_{1}, b_{2}$ corresponding correction.

Correcting expressions were obtained for $P_{B A S}, Q_{B A S}$ and coefficients $a_{0}, a_{1}, a_{2}, b_{0}, b_{1}, b_{2}$ calculation on the assumption of absolute unit load models with $U_{B A S 1}$ and $U_{B A S 2}$ invariance:

$$
\begin{gathered}
P_{B A S(2)}=P_{B A S(1)} \cdot\left(a_{0(1)}+a_{1(1)} \cdot \frac{U_{B A S(2)}}{U_{B A S(1)}}+a_{2(1)} \cdot\left(\frac{U_{B A S(2)}}{U_{B A S(1)}}\right)^{2},\right. \\
a_{0(2)}=\frac{P_{B A S(1)}}{P_{B A S(2)}} \cdot a_{0(1)}, \quad a_{1(2)}=\frac{P_{B A S(1)}}{P_{B A S(2)}} \cdot \frac{U_{B A S(2)}}{U_{B A S(1)}} a_{1(1)}, \quad a_{2(2)}=\frac{P_{B A S(1)}}{P_{B A S(2)}} \cdot\left(\frac{U_{B A S(2)}}{U_{B A S(1)}}\right)^{2} \cdot a_{2(1)}, \\
Q_{B A S(2)}=Q_{B A S(1)} \cdot\left(b_{0(1)}+b_{1(1)} \cdot \frac{U_{B A S(2)}}{U_{B A S(1)}}+b_{2(1)} \cdot\left(\frac{U_{B A S(2)}}{U_{B A S(1)}}\right)^{2}\right) \\
b_{0(2)}=\frac{Q_{B A S(1)}}{Q_{B A S(2)}} \cdot b_{0(1)}, \quad b_{1(2)}=\frac{Q_{B A S(1)}}{Q_{B A S(2)}} \cdot \frac{U_{B A S(2)}}{U_{B A S(1)}} b_{1(1)}, \quad b_{2(2)}=\frac{Q_{B A S(1)}}{Q_{B A S(2)}} \cdot\left(\frac{U_{B A S(2)}}{U_{B A S(1)}}\right)^{2} \cdot b_{2(1)} .
\end{gathered}
$$

The equations (2-5) using results are shown in Table 2.

Table 2. Polynomial load model coefficients, base active and reactive power with $U_{B A S 2}=6.0 \mathrm{kV}$

\begin{tabular}{|c|c|c|c|c|c|c|c|}
\hline \multicolumn{3}{|c|}{ Active power } & \multicolumn{4}{c|}{ Reactive power } \\
\hline$a_{0(2)}$ & $a_{1(2)}$ & $a_{2(2)}$ & $P_{\mathrm{BAS}(2)}, \mathrm{MW}$ & $b_{0(2)}$ & $b_{1(2)}$ & $b_{2(2)}$ & $Q_{\mathrm{BAS}(2)}, \mathrm{Mvar}$ \\
\hline 1.544 & -2.297 & 1.753 & 1.343 & 61.614 & -124.471 & 63.857 & 0.591 \\
\hline
\end{tabular}

Series of steady state mode calculation were repeated with corrected base active $P_{B A S}$ and reactive $Q_{B A S}$ power and per unit polynomial coefficients $a_{0}, a_{1}, a_{2}, b_{0}, b_{1}, b_{2}$ from Table 2 . Obtained results are shown in Fig. 2.

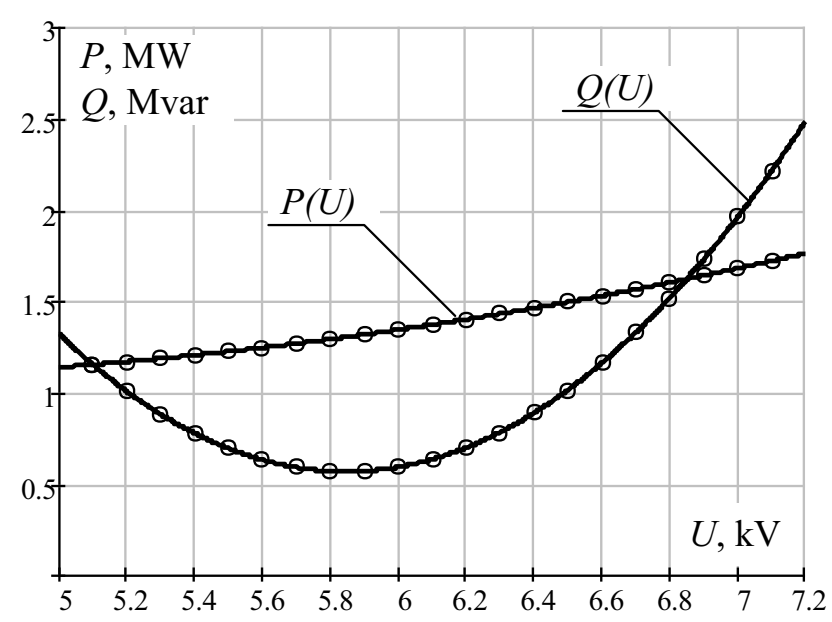

Figure 2. Original static load models with $U_{B A S 1}=6.2 \mathrm{kV}$ and "RastrWin" series of steady state mode calculation results with $U_{B A S 2}=6.0 \mathrm{kV}$ after correction 


\section{MATEC Web of Conferences}

In this case, the series of steady state mode calculation results correspond to original static load models, so presented calculation expressions (2-5) are correct.

\section{Conclusion}

Polynomial load model practical application in power system studies makes additional demand on source data input. This demand consists in load node base voltage invariance. Otherwise, static load models have difference from original characteristics, and calculation complementary error appears. If base voltage correction is necessary, the base active and reactive power and polynomial coefficients must be corrected too. Correcting calculation expressions (2-5) are presented in the paper.

\section{References}

1. J. Milanović, K. Yamashita, S. Martínez Villanueva, S. Djokić, and L. Korunović, IEEE Transactions on Power Systems, 28, 3038 (2013)

2. W. Price, C. Taylor, G. Rogers, K. Srinivasan, C. Concordia, B. Johnson, IEEE Transactions on Power Systems, 10, 1302 (1995)

3. A. Tavlintsev, A. Pazderin, O. Malozemova, P. Chusovitin, Proc. of 13th International Conference on Environment and Electrical Engineering, (Wroclaw, Poland, 2013)

4. V. Neuimin, "RastrWin" software package user guide, http://www.rastrwin.ru/download/Files/HELP_RastrWin3_29_08_12.pdf 